increase in prevalence of gout, the utilisation of urate lowering agents remained low. Only 1 in 4 patients with gout were prescribed urate lowering agents.

Acknowledgements: The Hospital Authority of Hong Kong

Disclosure of Interest: None declared

DOI: 10.1136/annrheumdis-2018-eular.6398

\section{SAT0377 THE BURDEN OF MONOSODIUM URATE CRYSTALS ASSESSED BY DUAL-ENERGY CT AND ULTRASONOGRAPHY IS NOT CORRELATED TO CARDIOVASCULAR RISK}

T. Pascart ${ }^{1}$, B. Capon ${ }^{2}$, A. Grandjean ${ }^{1}$, J. Legrand ${ }^{2}$, N. Namane ${ }^{2}$, E. Houvenagel ${ }^{1}$, L. Norberciak ${ }^{3}$, J.-F. Budzik ${ }^{2} .{ }^{1}$ Rheumatology; ${ }^{2}$ Radiology, ${ }^{3}$ Biostatistics, Hopital Saint Philibert, Lomme, France

Background: Gout is associated with higher cardiovascular risk and increases with disease severity. It is not clear if the monosodium urate (MSU) crystal burden is associated with traditional cardiovascular risk factors.

Objectives: The objective of this study was to explore the relationship between the extent of MSU deposition assessed with ultrasonography (US) and dualenergy CT (DECT) and cardiovascular risk.

Methods: Gout patients naive of urate lowering therapy were included in this cross-sectional study to undergo DECT scans for the assessment of total MSU volume deposition of the knees and feet, and US to evaluate the number of joints with the double contour (DC) sign among the femoro-patellar, talo-crural and first metatarsophalangeal joints. Participants were screened for traditional cardiovascular risk factors and levels of the ACC/AHA 10 year-risk for heart disease or stroke was calculated. The primary endpoint was the Spearman correlation coefficient $\rho$ between DECT MSU volume and cardiovascular risk.

Results: A total of 50 patients predominantly male (46/50) aged 62.6 years $( \pm 14.1)$ were included. Participants had gout duration of 9.5 years $( \pm 11.8)$, had experienced 4.1 flares $( \pm 6.3)$ over the past year, had serum urate (SU) levels of $8.1 \mathrm{mg} / \mathrm{dL}( \pm 2.3)$, and $35 / 50$ had at least one US tophus of $1.5 \mathrm{~cm} 3( \pm 1.8)$. The volume of MSU deposits with DECT was $3.9 \mathrm{~cm} 3( \pm 11.2)$ for the feet and $2 \mathrm{~cm} 3$ $( \pm 4.4)$ for the knees. Overall, 28 patients presented with the metabolic syndrome. Correlations between DECT volumes of MSU deposits of the knees, feet, and knees+feet were poor with $\rho$ respectively of $0.23,0.03$ and 0.21 . The was no correlation between the number of joints with the DC sign and cardiovascular risk ( $\rho$ of 0$)$ and the correlation was poor with SU levels $(\rho=0.09)$. Patients with the metabolic syndrome had similar DECT volume of MSU deposits than those without $(\mathrm{p}=0,29)$.

Conclusions: This study suggests that the association of gout with traditional cardiovascular risk factors is not related to the extent of the monosodium urate crystal burden.

Disclosure of Interest: None declared

DOI: 10.1136/annrheumdis-2018-eular.3822

\section{SAT0378 $\quad$ THE TREND OF TREG AND TH17 CELLS CHANGES IN P2X7R-REGULATED ACUTE GOUTY ARTHRITIS MODEL RATS}

X.-J. Dai ${ }^{1}$, J.-H. Tao ${ }^{1}$, X. Fang ${ }^{1}$, Q. Lin ${ }^{1}$, M.-Y.Li ${ }^{1}$, Y. Xia ${ }^{1}$, X.-M. Li ${ }^{1}$, X.-P. Li ${ }^{1}$, Y.P. Wang ${ }^{2} .{ }^{1}$ Rheumatology and Immunology, The First Affiliated Hospital of University of Science and Technology of China, Hefei, China; ${ }^{2}$ Centre for Transplantation and Renal Research, Westmead Institute for Medical Research, The University of Sydney, NSW, Australia

Background: ATP may be the second causative signal for the onset of gout, which acts on P2 $\times 7 \mathrm{R}$ to regulate the development of acute gouty arthritis. ${ }^{1}$ Both regulatory T cells and Th17 cells are important in the development and progression of inflammatory diseases. ${ }^{2}$

Objectives: To investigate the effect of P2 $\times 7 R$ on Treg and Th17 cells in acute gouty arthritis model of rats and its role in acute gouty arthritis.

Methods: Eighty male SD rats were randomly divided into three groups: After establishment of acute gouty arthritis model, rats were given P2 $\times 7 R$ agonist ATP, P2 $\times 7 R$ inhibitor BBG and PBS, respectively. The rats were sacrificed at 6 hour, 12 hour, 24 hour, 48 hour and 72 hour after treatment. The spleens of the rats were grinded and the expression of Treg and Th17 cells were detected by flow cytometry. Comparison the levels and the ratio of Treg and Th17 cells at the different time points.
Results: (1)The expression levels of Treg and Th17 in the spleen: After treatment at 12 hour, The expression levels of Treg and Th17 in the ATP group were significantly higher than that in the BBG and control groups $(p=0.001,0.021 ; p=0.01$, 0.025); The expression levels of Treg and Th17 in control group were higher than that in BBG group ( $p=0.021,0.044)$; There were no significant differences in the three groups at 72 hour after treatment $(p=0.052,0.116)$. (2). The expression trend of Treg and Th17 in different time points: the level of Treg was increased at 6 hour, but decreased gradually at 12 h, 24 hour and then increased at 48 hour again; The level of Th17 was increased at 6 hour, $12 \mathrm{~h}$ and 24 hour, but decreased gradually at 48 hour, 72 hour. (3). The ratio of Treg/Th17 gradually decreased in the first three time points, increased at 48 hour and 72 hour in three groups. The ratio of Treg/Th17 in ATP group was lower than that in BBG group and control group at 12 hour, with significant difference $(p<0.05)$. But at other four time poins, the ratios were no significant differences among the three groups.

Conclusions: Activation of P2 $\times 7 \mathrm{R}$ decreased the ratio of Treg/Th17 in acute gouty arthritis rat model that showed an acute change trend along with the time suggesting that P2 $\times$ 7R-regulated the ratio of Treg/Th17 cells affected acute gouty arthritis.

\section{REFERENCES:}

[1] Tao JH, Zhang Y, Li XP. P2X7R: a potential key regulator of acute gouty arthritis. Semin Arthritis Rheum 2013;43(3):376-380.

[2] Noack M. Th17 and regulatory T cell balance in autoimmune and inflam matory diseases. Autoimmunity reviews 2014;13(6):668-677.

Acknowledgements: This work was supported by grants from the National Natural Science Foundation of China (81671601).

Disclosure of Interest: None declared

DOI: 10.1136/annrheumdis-2018-eular.6136

\section{SAT0379 VACUUM-ASSISTED CLOSURE VERSUS CONVENTIONAL WOUND CARE IN THE MANAGEMENT OF CHRONIC ULCERS IN PATIENTS WITH TOPHACEOUS GOUT: A PROSPECTIVE ANALYSIS}

X. Pan, Z. Huang, M. Liu, D. Li, Z. Huang, Y. Huang, X. Huang, M. Liu, X. Li, X. Yao, Y. Wang, Q. Huang, X. Guo, S. Zheng, T. Li. Department of Rheumatology and Clinical Immunology, Guangdong Second Provincial General Hospital, Guangzhou, China

Background: With the rising epidemic of gout, an increasing number of patients suffer from chronic ulcers associated with tophaceous gout in China, causing poor quality of life and disability. Such ulcers are very difficult conditions to deal with. Vacuum-assisted closure (VAC) has been proved to be effective in treating a variety kinds of wounds such as diabetic foot ulcers. However, its use in chronic ulcers associated with tophaceous gout has been seldom reported.

Objectives: In the present study, we evaluated the use of VAC in the treatment of chronic ulcers associated with tophaceous gout in comparison to conventiona wound care (CWC).

Methods: We performed a 12 week prospective study that included 13 patients treated with VAC and 14 patients treated with CWC. We collected the clinical out comes of these patients and data from a satisfaction survey. Chronic ulcers were treated until wound closure, or until the end of 12 weeks. Study will discontinue when the ulcer worsens or remains unchanged by the end of week 4.

Results: Granulation tissue appeared in 12 (92.31\%) patients by the end of week 2 in the VAC group, while it appeared in 6 (42.86\%) patients by that time in the CWC group ( $p=0.013)$. 100\% granulation was achieved in $11(84.62 \%)$ patients by the end of week 8 in the VAC group as compared to $5(35.71 \%)$ patients by that time in the CWC group $(p=0.018)$. By the end of week 12 , decreasing in wound size was achieved in $12(92.31 \%)$ patients in the VAC group, while it was achieved in $10(71.43 \%)$ patients in the CWC group $(p=0.326)$. Among them, wound closure was achieved in $9(69.23 \%)$ patients in the VAC group, while it was achieved in 3 $(21.43 \%)$ patients in the CWC group $(\mathrm{p}=0.021)$. None developed local infection in both groups during the treatment. More patients in the VAC group were satisfied with treatment as compared to the CWC group. 


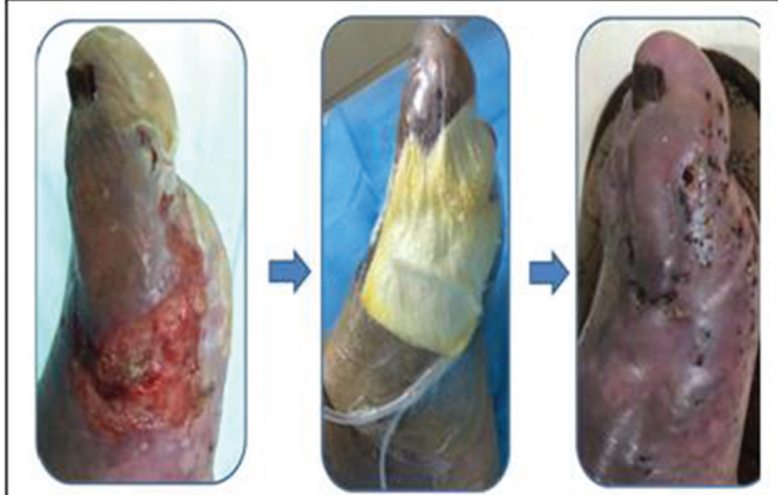

Figure 1. A 57-years old man, who suffered from ulcers associated with tophaceous gout for around 3 months, was successfully treated with VAC therapy.

Abstract SAT0379 - Figure 1. A 57-years old man, who suffered from ulcers associated with tophaceous gout for around 3 months, was successfully treated with VAC therapy.

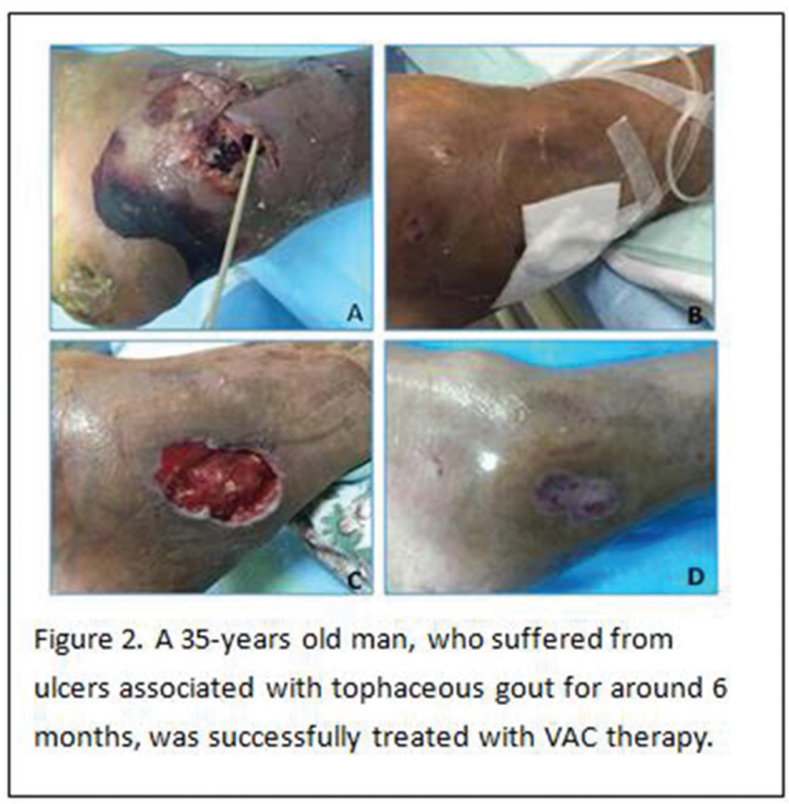

Abstract SAT0379 - Figure 2. A 35-years old man, who suffered from ulcers associated with tophaceous gout for around 6 months, was successfully treated with VAC therapy.

Conclusions: Our preliminary study suggests that VAC therapy is effective and safe in treating chronic ulcers associated with tophaceous gout and appears to be superior to CWC therapy. Large-scale studies are needed to further evaluated the efficacy and safety of the VAC therapy in the treatment of chronic ulcers associated with tophaceous gout.

\section{REFERENCE:}

[1] Agarwal J, Ogilvie ML, Lohman R, et al. Vacuum-assisted closure for sternal wounds: a first-line therapeutic management approach. [J]. Plastic \& Reconstructive Surgery 2015;116(4):1035-1040.

Acknowledgements: We are grateful to all the participants in our study. Disclosure of Interest: None declared

DOI: 10.1136/annrheumdis-2018-eular.5247
SATURDAY, 16 JUNE 2018

\section{Infection-related rheumatic diseases}

\section{SAT0380 \\ PANLAR-ACCAR RECOMMENDATIONS ON DIAGNOSIS AND TREATMENT OF CHIKUNGUNYA-RELATED INFLAMMATORY ARTHROPATHIES IN LATIN AMERICA}

P. Monge ${ }^{1}$ on behalf of PANLAR-ACCAR Consensus Group in Chikungunya in Latin America, A.M. Sapag ${ }^{2}$, I.Y. Moreno ${ }^{3}$, R.A. Montúfar ${ }^{4}$, V. Khoury ${ }^{5}$, P. Camilo ${ }^{5}$ R.E. Rivera ${ }^{6}$, J.C. Rueda ${ }^{7}$, D. Jaramillo-Arroyave ${ }^{8}$, J. Londoño ${ }^{9}$, M.C. Ruiz ${ }^{10}$, F. Fernández-Castillo ${ }^{11}$, M. Quintero ${ }^{12}$, Y. Fuentes $^{13}$, J.L. Aguilar ${ }^{14}, \mathrm{C}$. V. Caballero-Uribe ${ }^{15}, \mathrm{H}$. Sandoval ${ }^{16}$, C. Pineda ${ }^{16}$ on behalf of Pan-American League of Associations for Rheumatology (PANLAR), in collaboration with the Central American, Caribbean and Andean Rheumatology Association (ACCAR by its Spanish acronym). ${ }^{1}$ Asociacion Costarricense De Reumatologia, San Jose, Costa Rica; ${ }^{2}$ Sociedad Boliviana de Reumatología, Santa Cruz, Bolivia, Plurinational State Of, ${ }^{3}$ Sociedad Panameña de Reumatología, Panama City, Panama; ${ }^{4}$ Asociación Salvadoreña de Reumatología, San Salvador, El Salvador ${ }^{5}$ Sociedad Dominicana de Reumatología, Santiago, Dominican Republic;

${ }^{6}$ Asociación Guatemalteca de Reumatología, Guatemala City, Guatemala;

${ }^{7}$ Asociación Colombiana de Reumatología, Chia; ${ }^{8}$ Asociación Colombiana de Reumatología, Medellin; ${ }^{9}$ Asociación Colombiana de Reumatología, Bogotá, Colombia; ${ }^{10}$ Sociedad Venezolana de Reumatología, Maracay; ${ }^{11}$ Sociedad Venezolana de Reumatología, Barquisimeto; ${ }^{12}$ Sociedad Venezolana de Reumatología, Mérida; ${ }^{13}$ Sociedad Venezolana de Reumatología, Ciudad Bolívar, Venezuela, Bolivarian Republic Of, ${ }^{14}$ Sociedad Peruana de Reumatología, Lima, Peru; ${ }^{15}$ Asociación Colombiana de Reumatología, Barranquilla, Colombia;

${ }^{16}$ Instituto Nacional de Rehabilitación, México City, Mexico

Background: Although mortality rates related with Chikungunya $(\mathrm{CHIK})$ outbreaks into Latin America's endemic-dengue rural and new urban regions are low dealing with symptoms and sequelae can produce both a significant burden of disease and diminish quality of life — from many months to years — after the acute phase of infection, with a significant impact on public and individual health.

Objectives: The aim of this work was to establish a PANLAR-ACCAR consensus on diagnosis and treatment of CHIK-related inflammatory arthropathies transmitted by Ae. Aegypti and Ae. Albopictus in Latin America (LA).

Methods: Based on the Consensus Development Conference format, a panel of ACCAR rheumatologists $(n=10)$ took part in this PANLAR initiative. Experts voted recommendations from a previous content analysis of the medical literature on CHIK, four subsequent topic's Conferences and a workshop. Consensus represents the majority agreement ( $\geq 80 \%$ ) achieved for each recommendation.

Results: The panel reach four overarching principles: 1) $\mathrm{CHIK}$ virus (CHIKV) is a re-emergent virus transmitted by two species of mosquitoes: Ae. Aegypti and Ae. Albopictus; 2) CHIKV caused massive outbreaks in LA; 3) Chronic CHIKV infection produces an inflammatory joint disease that in some cases can last several months to years, and 4) Currently, there are no vaccines or antivirals available for CHIKV infections.

Conclusions: PANLAR-ACCAR achieve 13 recommendations on CHIK categorised in three groups: 1) epidemiology and clinical manifestations; 2) diagnosis, and 3) treatment, representing the consensus agreement from the panel's members.

\section{REFERENCES:}

[1] Pineda C, Munoz-Louis R, Caballero-Uribe CV, Viasus D. Chikungunya in the region of the Americas. A challenge for rheumatologists and health care systems. Clin Rheumatol 2016;35(10):2381-5.

[2] Fernandez-Salas I, Danis-Lozano R, Casas-Martinez M, Ulloa A, Bond JG Marina CF, et al. Historical inability to control Aedes aegypti as a main contributor of fast dispersal of chikungunya outbreaks in Latin America. Antiviral Res 2015;124:30-42.

[3] Khoury VJ, Camilo PR. Chikungunya virus (CHIKV): what can be expected after the acute phase? Reumatol Clin 2016;12(1):1-3.

[4] JC Rueda, J-I Angarita, AM Santos, E-L Saldarriaga, I Pelaez-Ballestas, MJ Soares-Santeugini, J Londono. SAT0576

[5] Improved clinical scenario for chikungunya diagnosis Annals of the Rheumatic Diseases 2017 Jun;76(Suppl 2):994.

Disclosure of Interest: None declared

DOI: 10.1136/annrheumdis-2018-eular.6980 